\title{
An Experimental Study on the Darrieus-Savonius Turbine for the Tidal Current Power Generation"
}

\author{
Yusaku KYOZUKA** \\ **Faculty of Engineering Sciences, Kyushu University \\ 6-1 Kasuga Koen, Kasuga, Fukuoka 816-8580 Japan \\ E-mail: kyozuka@esst.kyushu-u.ac.jp
}

\begin{abstract}
The Darrieus turbine is popular for tidal current power generation in Japan. It is simple in structure with straight wings rotating around a vertical axis, so that it has no directionality against the motion of tidal flow which changes its direction twice a day. However, there is one defect in the Darrieus turbine; its small starting torque. Once it stops, a Darrieus turbine is hard to re-start until a fairly fast current is exerted on it. To improve the starting torque of the Darrieus turbine used for tidal power generation, a hybrid turbine, composed of a Darrieus turbine and a Savonius rotor is proposed. Hydrodynamic characteristics of a semi-circular section used for the Savonius bucket were measured in a wind tunnel. The torque of a two bucket Savonius rotor was measured in a circulating water channel, where four different configurations of the bucket were compared. A combined Darrieus and Savonius turbine was tested in the circulating water channel, where the effect of the attaching angle between Darrieus wing and Savonius rotor was studied. Finally, power generation experiments using a 48 pole electric generator were conducted in a towing tank and the power coefficients were compared with the results of experiments obtained in the circulating water channel.
\end{abstract}

Key words: Tidal Current Power Generation, Darrieus-Savonius Turbine, Model Test, Starting Torque, Torque Coefficient, Power Coefficient, Single Stream Tube Theory

\section{Introduction}

Promotion of the utilization of natural energy is urgent as a countermeasure against global warming. There are several kinds of energy resources in the ocean but the utilization of ocean energy is far behind other natural energies such as wind, solar, ground thermal, small and medium hydraulic plants and biomass. Since the density of water is 800 times greater than air density and the power of the flow is proportional to the cube of the fluid velocity, the power of an ocean current of 2 knots is equal to a wind flow of $9 \mathrm{~m} / \mathrm{s}$. There are some narrow channels in Japan such as the Naruto Channel, where the maximum current velocity is about 10 knots and the total power of the current is enormous. This is an appropriate location to propose this kind of project utilizing the ocean current to reduce carbon dioxide.

We have been conducting an experimental study of tidal power generation since 2005 at the Tastuno-seto strait, Nagasaki Prefecture. We chose a Darrieus turbine as the water turbine because the tidal current changes direction periodically. The Darrieus turbine has a vertical axis of rotation and therefore is omni directional to tidal current. The Darrieus turbine is one of the effective turbines that utilizes the lift of the rotating wings but its structure becomes very simple if straight wings are adopted. Some examples of this application have been used in Japan. ${ }^{1), 2), 3), 4)}$

There is in Darrieus turbine, however, one defect: its small starting torque. Once it 
stops, a Darrieus turbine is hard to re-start until a fairly fast current is exerted on it. A forced periodic rotation or motoring technique is usually used for wind turbines if a power grid is available at the site. But the starting torque of the turbine is very important if a power grid is not available, which may be the case in tidal current power generation

In this report, we propose a Darrieus-Savonius combined turbine to improve the small starting torque of a Darrieus turbine since a Savonius rotor generates large torque in the low speed range, whereas the Darrieus turbine generates large torque primarily in the high speed range. First, the hydrodynamic force of the semi-circlular section which is used as the bucket of the Savonius rotor was measured in a wind tunnel. Then, the torque of the rotational axis of the Savonius rotor in four configurations of two buckets was measured in a circulating water channel. From the results of the tests, we adopted a configuration of the Savonius rotor to combine with the Darrieus turbine with two wings. We measured the torque of the combined turbine in the circulating water channel, altering the attaching angle between the Darrieus wing and the Savonius bucket. We confirmed the improvement of the starting torque of the combined turbine, but at the same time we found that the maximum torque at the high rotational velocity ratio was decreased by $30 \%$ compared with the torque by the solo Darrieus turbine. To solve this problem, a ratchet mechanism or one way clutch mechanism between the Darrieus turbine and Savonius rotor was tested to avoid the negative torque which might be generated by the Savonius rotor.

Finally, electric generation experiments were conducted in the towing tank to confirm the starting torque characteristics of the Darrieus-Savonius turbine and the power coefficients were evaluated in comparison with the results obtained in the circulating water tank.

\section{Hydrodynamic characteristics of Darrieus-Savonius turbine}

\subsection{Wind Tunnel Tests of the Bucket of the Savonius Rotor}

The Savonius rotor was originally devised by S.J. Savonius in the 1920s. It is classified as a drag-type turbine consisting of several semi-circlular buckets. The characteristics of the Savonius rotor are its simplicity in structure and the large starting torque in a slow flow. The Savonius rotor has a vertical rotating axis as does the Darrieus turbine so that they can be combined into one unit.

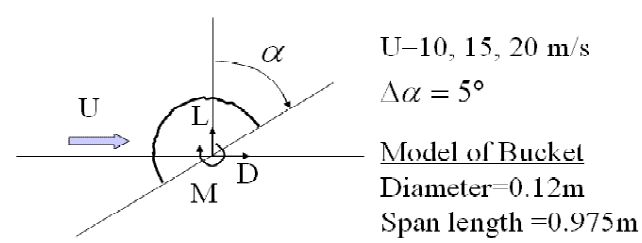

Fig.1 Angle of attack of the model in the wind tunnel tests

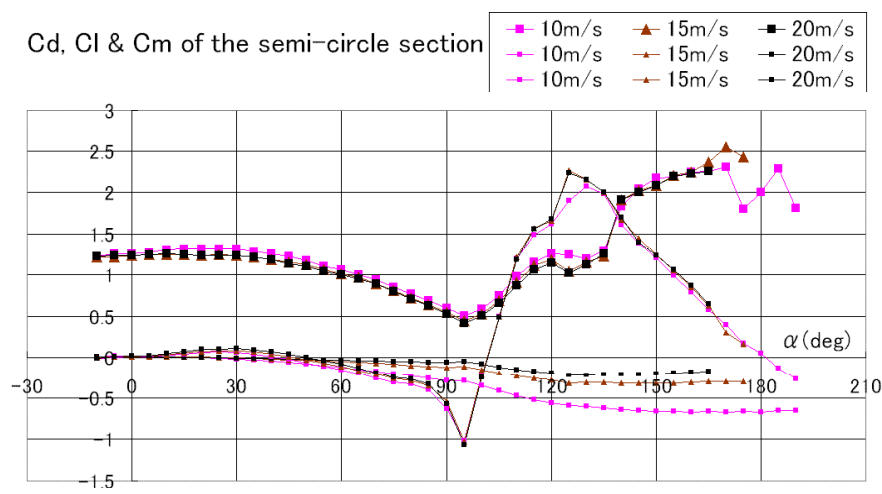

Fig.2 Hydrodynamic coefficients of a semi-circular section in the steady winds 


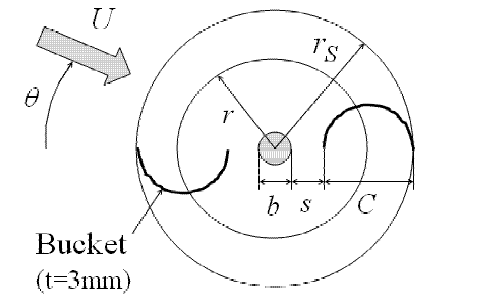

Fig. 3 Definition of Savonius rotor
Table 1 Configuration of buckets of Savonius rotor

\begin{tabular}{|c|c|c|}
\hline & $\mathrm{s}(\mathrm{mm})$ & $\mathrm{r}_{\mathrm{S}}(\mathrm{mm})$ \\
\hline Case-1 & -36 & 94 \\
\hline Case-2 & -26 & 104 \\
\hline Case-3 & 4 & 134 \\
\hline Case-4 & 24 & 154 \\
\hline
\end{tabular}

C: $120 \mathrm{~mm}, \mathrm{~b}: 20 \mathrm{~mm}$

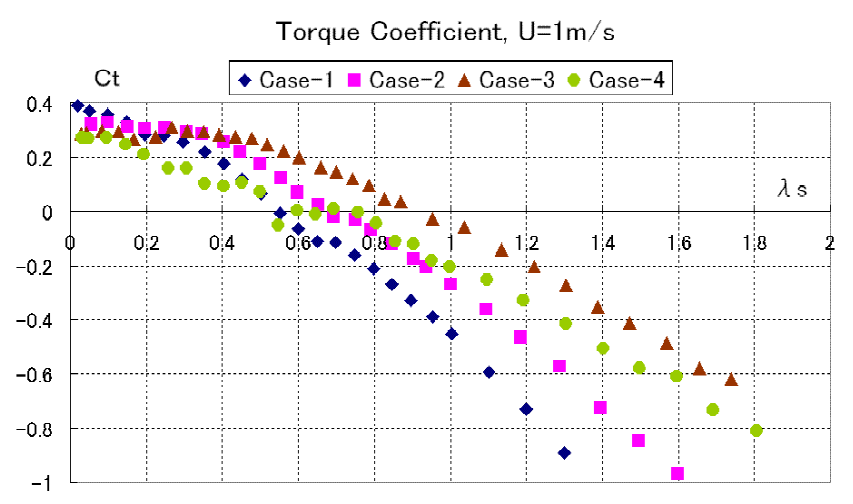

Fig.4 Torque coefficient of Savonius rotors, $U=1 \mathrm{~m} / \mathrm{s}$

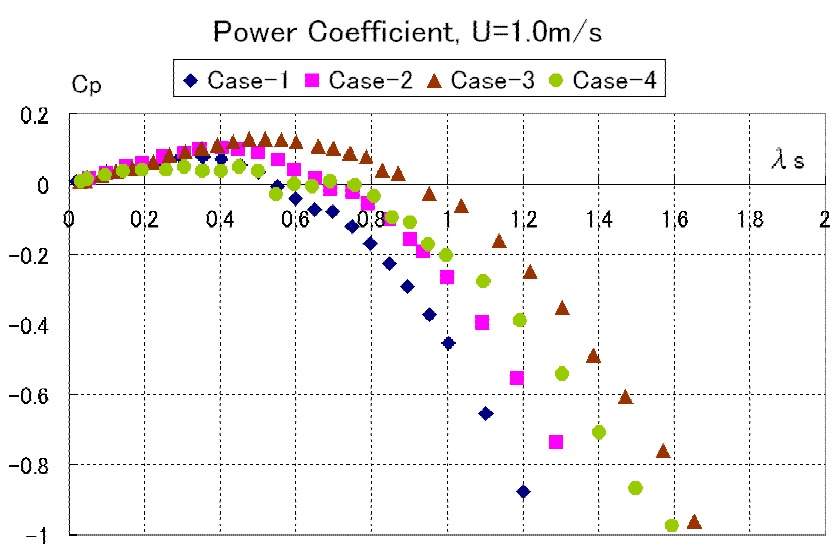

Fig. 5 Power coefficient of Savonius rotors, $U=1 \mathrm{~m} / \mathrm{s}$

To understand the hydrodynamic characteristics of the bucket of a Savonius rotor, we measured the drag, lift and moment acting on the semi-circular section in the wind tunnel of the Research Institute for Applied Mechanics, Kyushu University. The diameter of the bucket model is $0.12 \mathrm{~m}$ and the span length is $0.975 \mathrm{~m}$ with the endplates. The definition of the angle of attack is shown in Fig.1. Because of the symmetry of the model, we made measurements for half directions and obtained the results at three wind speeds, 10, 15 and $20 \mathrm{~m} / \mathrm{s}$. Fig. 2 shows the lift, drag and moment coefficients of the semi-circular section used as the bucket of the Savonius rotor. The lift and drag coefficients are found to fluctuate near the attack angle of 90 degrees. The moment coefficient is found to depend slightly on the flow velocity but there is no such effect on the lift or drag coefficient. The thickness of the model made from acrylic pipe may be a problem because of its rigidity in the high speed wind experiments. These coefficients are used in the analysis of the torque of the Savonius rotor by the single stream tube theory. 


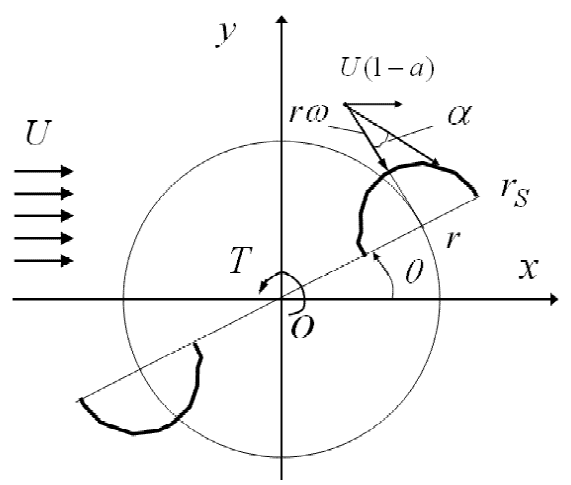

Fig. 6 Coordinate system of the analysis of Savonius turbine

\subsection{Tests of the Savonius rotor in the circulating water channel}

Torque of a two bucket Savonius rotor was measured in the circulating water channel. We tested the Savonius rotor in the four configurations shown in Fig.3 and Table 1. This rotor usually consists of two pairs of buckets in the span direction shifting the attaching angle by 90 degrees. We used a half part of the Savonius rotor with two buckets and added it to the existing Darrieus turbine with its rotating axis. Measured torque is normalized as

$$
C_{t}=\frac{\bar{T}}{0.5 \rho r_{S} A_{S} U^{2}}
$$

where $\bar{T}$ denotes the mean torque of $T$ in the cycle and $A_{S}=2 r_{S} L_{\text {span }}$ is the projected area of the rotor.

The velocity of the flow was varied by $\mathrm{U}=0.6,0.8$ and $1.0 \mathrm{~m} / \mathrm{s}$ in the experiments and the velocity ratio of the rotor is defined as:

$$
\lambda_{S}=\frac{r_{S} \omega}{U}
$$

Fig. 4 shows the results of torque coefficients in four cases. Case-1 shows the good performance near $\lambda_{S}=0$, which is equal to the starting torque, but it becomes negative at $\lambda_{S}$ greater than 0.6. On the other hand, Case-3 shows good performance over a wide range of $\lambda_{S}$. Torque performance of Case-4 was worse than Case-3, indicating that the gap between the rotating axis and the bucket may reduce the torque of the rotor.

Fig.5 shows the power coefficient of the Savonius rotor. Maximum $C_{P}$ is obtained as 0.16 in Case-3, which is smaller than the 0.24 by Sheldahl et al. ${ }^{(5)}$ who used two overlapping buckets without a rotating axis.

\subsection{Calculation of torque of the Savonius rotor by the single stream tube theory ${ }^{(6)}$}

The single stream tube theory is similar to the elementary wing theory taking account of the flow decrease effect by the resistance of the turbine. Let us calculate the flow resistance of the Savonius rotor rotating with angular frequency $\omega$ by the momentum theory. If the flow velocity at infinity is given by $U(1-2 a)$, the velocity at the rotor is given by $U(1-a)$. Then, the flow decrease ratio is given by the momentum theory as:

$$
a=\left(1-\sqrt{1-C_{F X}}\right) / 2
$$

where $C_{F X}$ is the resistance coefficient of the turbine.

In Fig.6, let us denote the lift, drag and moment of the rotating bucket by $L, D, M$, then torque at the origin is given as follows:

$$
T=L \times r \sin \alpha-D \times r \cos \alpha-M
$$




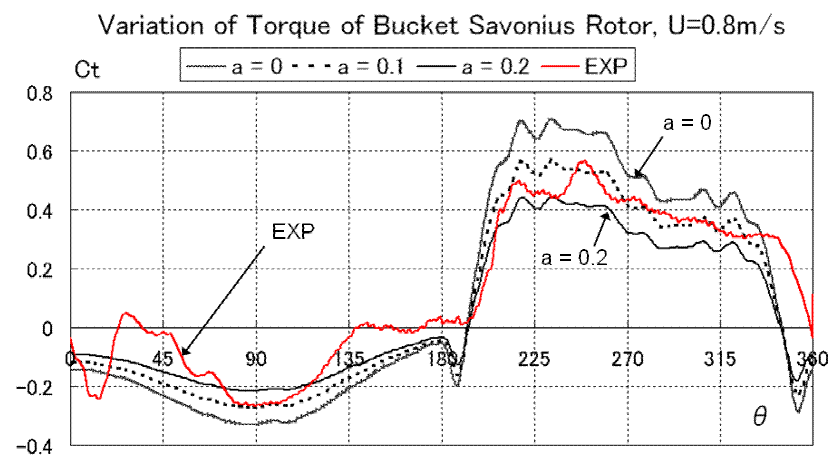

Fig.7 Variation of torque of one bucket Savonius rotor during one cycle, comparison of an experiment with the single stream tube theory

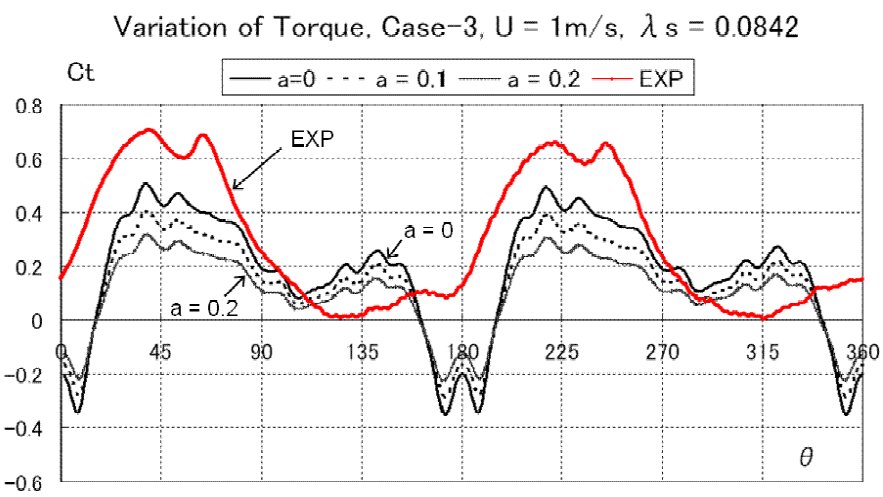

Fig.8 Variation of torque of two bucket Savonius rotor during one cycle, comparison of an experiment with the single stream tube theory

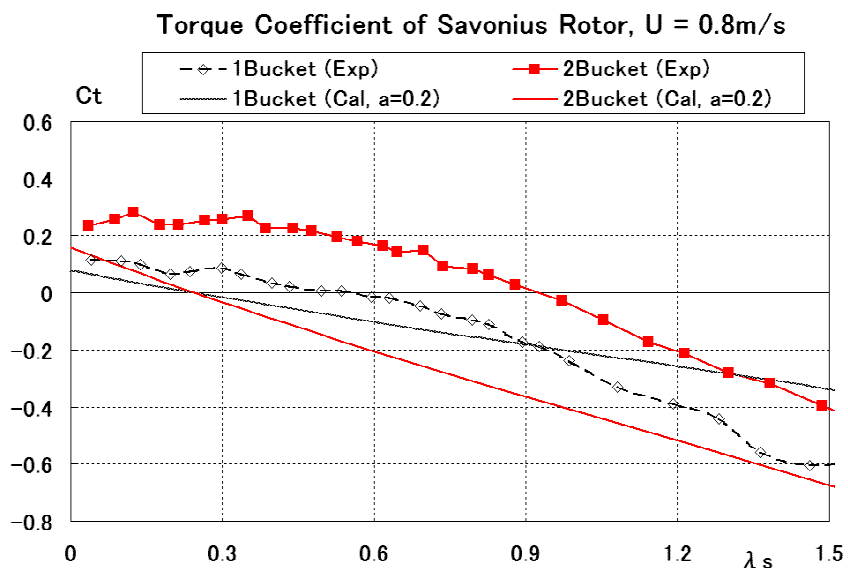

Fig.9 Comparison of torque coefficients of Savonius rotor of Case-3 between the single stream tube theory and experiments

where $\alpha$ stands for the attack angle of wing as:

$$
\alpha=\frac{\pi}{2}-\theta-\tan ^{-1} \frac{\lambda \cos \theta}{1-a+\lambda \sin \theta}
$$

where $\lambda$ denotes the velocity ratio of bucket as:

$$
\lambda=r \omega / U
$$

$C_{F X}$ of (3) is given by the mean resistance of the rotor as:

$$
C_{F X}=\frac{\bar{F}}{\rho r U^{2}}
$$

where $\bar{F}$ is calculated as follows: 


$$
\bar{F}=\frac{1}{2 \pi} \int_{0}^{2 \pi}\{L \cos (\alpha+\theta)+D \sin (\alpha+\theta)\} d \theta
$$

In the calculation, we obtain $C_{F X}$ iteratively by (3) and (7), and the torque is obtained by (4).

Fig. 7 shows the comparison of the single stream tube theory with the experimental results of the torque of one bucket rotating slowly at $\lambda_{s}=0.0842$. In this case, the single stream tube theory with the decelerated ratio $\mathrm{a}=0.1$ agrees fairly well with the experiments, although there is small discrepancy in the angles from 0 to 180 degree.

Fig. 8 shows the similar comparison of the Savonius rotor with the two buckets of Case-3. In this case, the theory is obtained by the superposing the two single bucket results shifting the angle by 180 degrees, so that the single stream tube theory neglects the hydrodynamic interactions between buckets. Theoretical results show negative torque near 0 and 180 degrees but the experimental results show positive torque along all the angles, which may be positive effects by the hydrodynamic interactions between the two buckets.

Fig. 9 shows the comparison of torque coefficients by the single stream tube theory with experiments in the velocity ratio $\lambda_{S}$ for two cases: the single bucket rotor and the two bucket rotor of Case-3. Experimental results are larger than the theory and the velocity ratio of zero torque of the experiments is several times larger than the theory. The theoretical results of two buckets are simply obtained as twice the theory of the single bucket. The experiments of two buckets are found to be parallel to the single bucket results on the positive side, which may be caused by the result of the hydrodynamic interactions.

From these results, the single stream tube theory is not appropriate for estimation of torque of the Savonius rotor because it neglects the hydrodynamic interactions between buckets, while this rotor generates large torque by making use of the hydrodynamic interactions.

\subsection{Test of a Darrieus-Savonius turbine in the circulating water channel}

From the results of Savonius rotors, we chose Case-3 and combined it with a Darrieus turbine as shown in Fig. 10. The span length of the Savonius rotor was $0.475 \mathrm{~m}$ although the span of the Darrieus wings was $0.6 \mathrm{~m}$. Since the effect of the attachment angle $\beta$ between the Darrieus wing and Savonius bucket was thought to be important on the torque and the power of the combined turbine, the experiments were conducted by changing $\beta$ by $0,45,90,135$ degrees.

Fig. 11 shows the blade section of the Darrieus turbine, which is the same as NACA0018 in thickness but has a circular camber. The particulars of the blade are shown in Table 2. The experimental results of the combined turbine are normalized as follows:

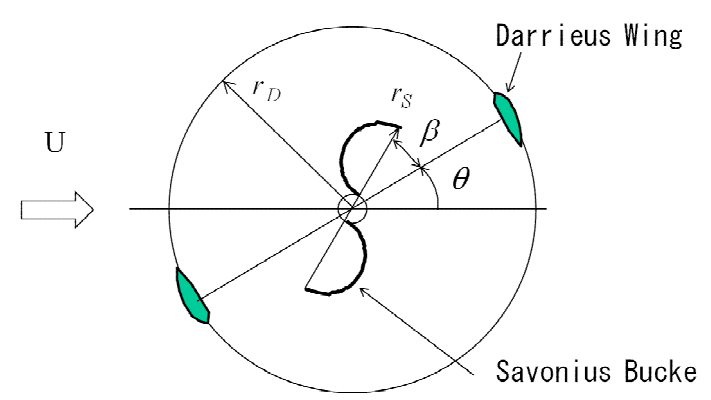

Fig. 10 Configuration of Darrieus wings and Savonius buckets ( $r_{D}$ : radius of Darrieus turbine, $r_{S}:$ radius of Savonius rotor )

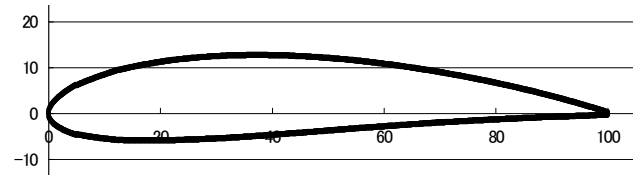

Fig.11 Darrieus wing section (NACA0018 with circular camber)

Table 2 Particulars of the blade of Darrieus turbine

\begin{tabular}{|c|c|}
\hline & NACA0018-C \\
\hline Chord (C) (mm) & 100 \\
\hline Span (S) (mm) & 600 \\
\hline Camber & Circular \\
\hline Solidity (2-Blades) & 0.106 \\
\hline Material & Aclyl \\
\hline
\end{tabular}




$$
\begin{aligned}
\lambda & =r_{D} \omega / U \\
C_{t} & =\frac{T}{0.5 \rho r_{D} A U^{2}}, \quad C_{P}=\frac{T \omega}{0.5 \rho A U^{3}}=\lambda \cdot C_{t}
\end{aligned}
$$

where $r_{D}$ stands for the radius of the Darrieus turbine, and $A=2 r_{D} \cdot L_{s p a n}$ is the projected area

Fig. 12 shows the torque coefficients for five cases including that without the Savonius rotor. First, the torque coefficient of solo Darrieus is definitely greater than other combined turbines near $\lambda \approx 2.2$ where the turbine is expected to generate the electricity, since the control unit controls the speed of the turbine at the highest peak of the power coefficient in the actual power generation.

On the other hand, the torque coefficient of solo Darrieus near $\lambda \approx 0$ is minimal among the cases, which was the reason we introduced the Savonius rotor to the Darrieus turbine. From these results, we understand the effect of the Savonius rotor on the starting torque in all cases, but there is some difference in its effect depending on the angle $\beta: 90$ or 135 degrees showed better results than 45 degrees. The torque of the combined turbines near $\lambda \approx 2.2$ is decreased to $70 \%$ of the solo Darrieus. The curve of torque coefficient of the solo Darrieus crosses other curves near $\lambda \approx 1.4$, so that the Savonius rotor generates a positive torque below $\lambda \leq 1.4$ and a negative torque above $\lambda \geq 1.4$.

Let us consider this from the experimental results of the Savonius rotor. The torque of the solo Savonius rotor is positive below $\lambda_{S} \approx 0.9$ in Fig.9, which is equivalent to $\lambda \approx 2$ for the combined turbines. If the torque of the combined turbines was given by the superposition of the solo Darrieus turbine and solo Savonius rotor, it would be enlarged below $\lambda \approx 2$ but it actually becomes smaller below $\lambda \approx 1.4$. Therefore, the performance of the combined turbine is not explained by the superposition of the independent cases. The interactions between the Darrieus turbine and the Savonius rotor are thought to be essential.

For confirmation of these circumstances, let us compare the torque variations during one cycle of the rotation. Fig. 13 shows the variation of torque coefficients of the combined turbines including solo Darrieus during one cycle at $\lambda=0.06$, a very slow rotational rate: the torque of the solo Darrieus is rather smaller than others of the combined turbines. The torque of the combined turbines becomes large at certain angles, twice a cycle, depending on $\beta$. Since the torque coefficient of the turbine is given by the mean value during a cycle, we understand the results of Fig.12.

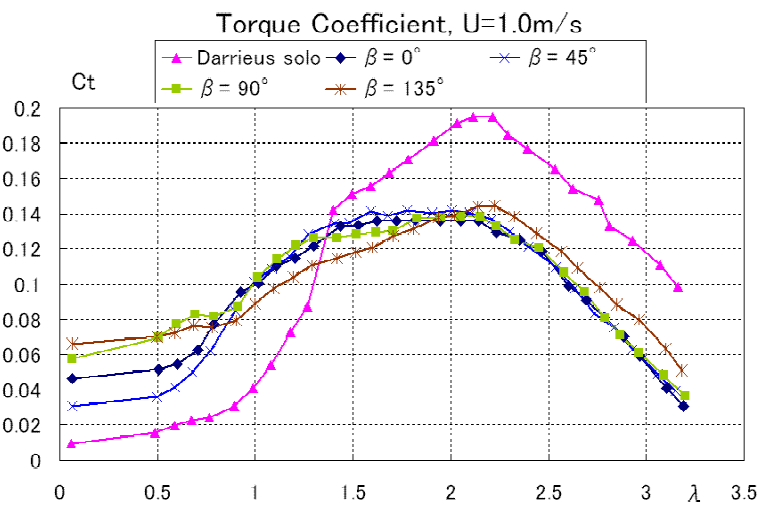

Fig.12 Torque coefficient of a Darrieus-Savonius turbine of the attachment angle $\beta$

Variation of Torque Coefficient, $U=1.0 \mathrm{~m} / \mathrm{s}, \lambda=0.06$

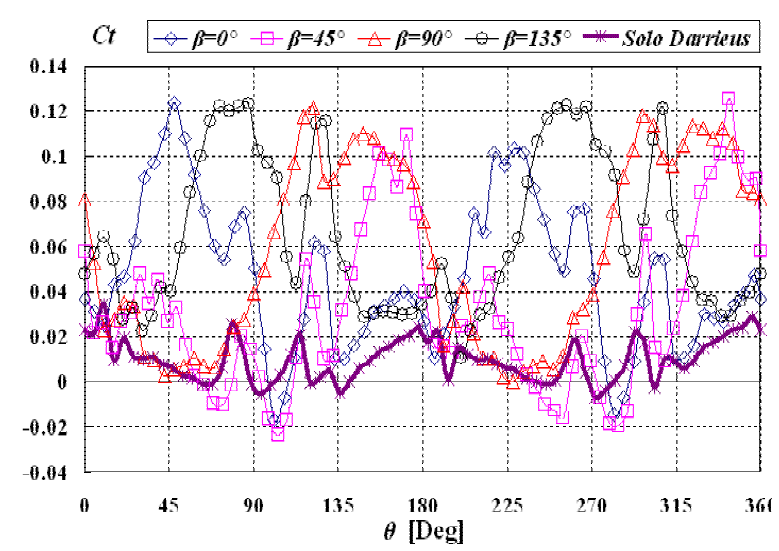

Fig.13 Variation of torque of the turbines during one cycle at $\lambda=0.06$ 
Next, Fig. 14 shows a similar comparison of the torque variation at $\lambda=2.0$, near the velocity ratio where the turbine is expected to generate the electricity. In this case, the torque by the solo Darrieus is larger than those of the combined turbines near the angles at 180 and 360 degrees, therefore we understand the reason why the torque coefficient of the solo Darrieus is larger than those of the combined turbine. In the case of $\beta=0$, the torque variation is negative at $\theta=120,300$ degrees, so that the mean value becomes small. The peaks of the torque variation are found around 180 and 360 degrees in all cases. From these results, the torque of the combined turbine might be generated primarily by the Darrieus wings near the velocity ratio, $\lambda=2.2$.

Fig. 15 shows the power coefficients of solo Darrieus and Darrieus-Savonius turbines in

$\lambda$. The maximum of the power coefficient of the solo Darrieus is attained as $C_{P}=0.43$ at $\lambda=2.2$ but they are reduced by $30 \%$ for the other combined turbines, which is clearly an unwanted change.

\subsection{Effect of the ratchet mechanism or one-way clutch attached to the Savonius rotor}

As shown by the results of the preceding section, the power generation of the Darrieus-Savonius combined turbine was found to drop by $30 \%$, which is too bad for the compensation of the enhancement of the starting torque. To improve the performance of the combined turbine, we tested the applicability of the ratchet mechanism or one-way clutch on the Savonius rotor. In fact, even though the Darrieus wings generate a large torque and the Savonius rotor may generate a negative torque at the same time at $\lambda=2.2$, the total torque of the combined turbine results in performance degradation. If this is true, introduction of the ratchet mechanism may solve the negative torque of the Savonius rotor, and the torque generated by the Darrieus wings might be maintainable as the total torque of the combined

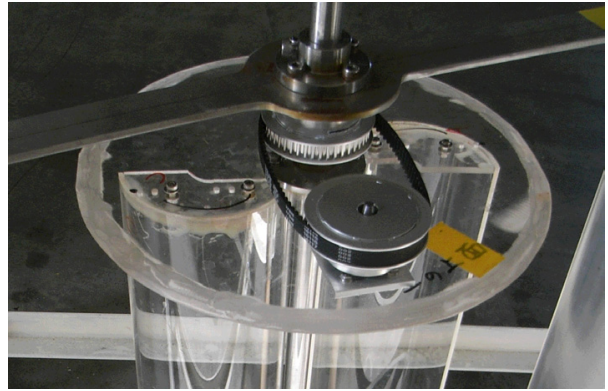

Fig. 16 Ratchet mechanism attached on the Savonius rotor 
turbine.

Fig. 16 shows a photo of the one-way clutch attached to the Savonius rotor used in the experiments; a pulley attached at the rotating shaft is linked to the clutch on the Savonius rotor by the belt. If the Savonius rotor generates anti-clockwise torque, the torque is transmitted to the rotating shaft, but if it generates clockwise torque, the torque is not transmitted to the shaft because of the idling of the one-way clutch.

Fig. 17 shows the torque coefficient of the Darrieus-Savonius turbines including one with the ratchet mechanism obtained in the towing tank experiments. The torque of the combined turbine with the ratchet mechanism is found to be largest in $\lambda>1.6$ but the difference is small among the other combined turbines. It is

Torque Coefficint, $U=1.0 \mathrm{~m} / \mathrm{s}$, Towing Tank

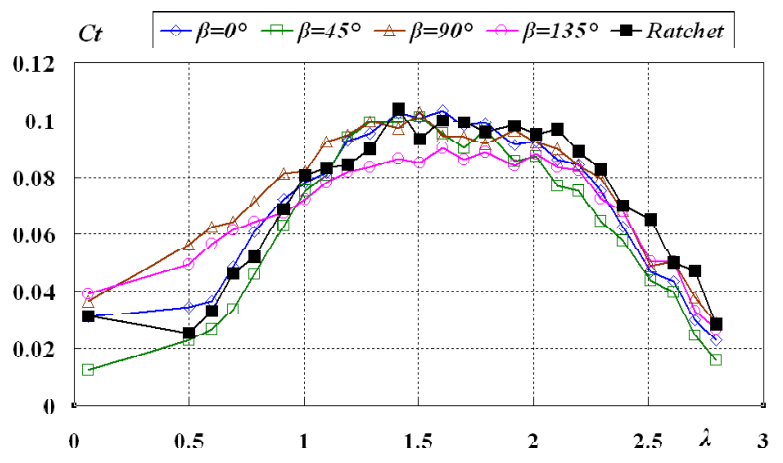

Fig.17 Torque coefficient of Darrieus-Savonius turbines including one with the ratchet mechanism in the towing tank experiments

\section{still smaller than the torque of}

the solo Darrieus turbine shown in Fig. 12. Thus, the reason the torque of the combined turbines is smaller than the solo Darrieus might be explained by the flow field being changed by the Savonius rotor, which may reduce the torque generated by the Darrieus wings. The attachment angle $\beta$ of the combined turbine with ratchet is indefinite and therefore the starting torque is also indefinite. From these results, we conclude that the ratchet mechanism is not effective in improving the performance of the combined turbine.

Comparing Fig. 12 with Fig. 17, we found that the torque coefficients in the towing tank experiments were lower by $30 \%$ than those in the circulating water channel. This might be explained by the difference in the turbulence of the flow between the two tanks. That is, the flow in the circulating water channel might be fully turbulent whereas the flow in the towing tank might be laminar. We plan to clarify this in future work.

\section{Power generation tests in the towing tank}

The power system of the tidal power generation may be independent from the electric power grid at present in the initial stage of the project and the construction site is generally at an isolated location. Therefore, the starting performance of the turbine is important and a power generation test is necessary to check this. We conducted power generation tests in the towing tank of the Research Institute for Applied Mechanics, Kyushu University, which is (Length) $\mathrm{x}$ (Breadth) $\mathrm{x}($ depth $)=65 \mathrm{~m} \times 5 \mathrm{~m} \times 7 \mathrm{~m}$ in size. A coreless generator or a three phase AC brushless generator with 48 poles, (rated power : $1 \mathrm{~kW}$ ) was connected directly to

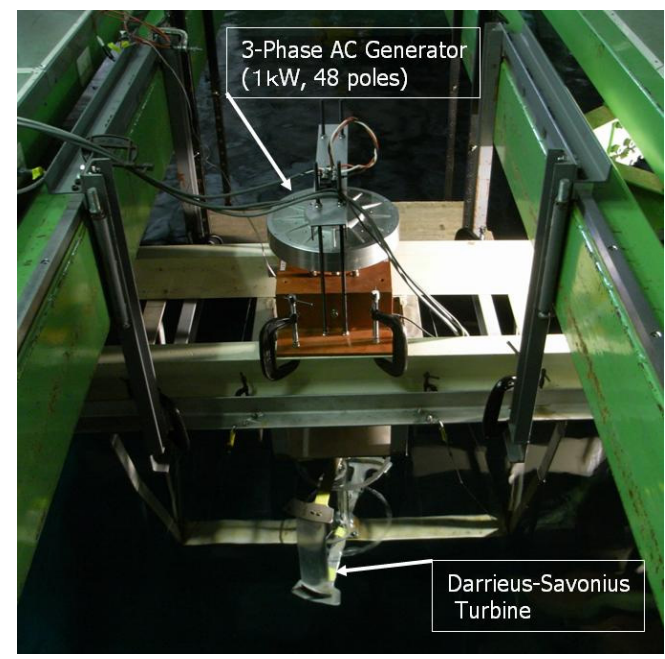

Fig.18 Power generation apparatus on the towing carriage 
the turbine without speed-up gears. Fig.18 shows a photo of the experimental apparatus on the towing carriage.

In these power generation experiments, the torque, rotational speed of the turbine, pulse signal to detect the Darrieus wing angle, voltage and current of the generator were measured. Eight resistances were used as the load of the generator and were selected by the changeover switch. In the experiments, the generator was free from the load when the towing carriage started to run and resistance was switched just after the turbine began its rotation. Fig. 19 is an example of the time series during the experiment, torque of the turbine, the pulse signal at $\theta=90$ degrees, and the output DC voltage. We can see in the figure that the turbine rotates rapidly at the beginning of the experiment but slowly after the load is exerted.

Fig. 20 shows the power coefficients of the solo Darrieus turbine and Darrieus-Savonius combined turbines including one with a ratchet mechanism in the power generation experiments. The power is calculated from the generated voltage and the resistance, so it includes the power conversion efficiency of the generator which is estimated as $70 \%$ by data in the manufacturer's catalog. The catalog data for the power conversion efficiency are given as $65.94 \%$ for 25 watt, $74.83 \%$ for 50 watt and $76.92 \%$ for 100 watt in the $100 \mathrm{rpm}$ tests, while the electric power was from 10 to 45 watt and the rotational speed was 30 to $70 \mathrm{~min}^{-1}$ in our experiments. The solo Darrieus turbine shows good performance: $C_{P}=0.24$ near $\lambda=2.2$. Therefore, the power coefficient of the turbine itself is about 0.34 for the solo Darrieus turbine. On the other hand, the performance of the Darrieus-Savonius turbines is nearly $20 \%$ below the solo Darrieus turbine. The effect of the ratchet mechanism is not large although the power coefficient of the turbine with this mechanism is the largest of the combined turbines, and the rotational speed ratio for the load free condition lies at $\lambda=3.1$ between those of solo Darrieus $(\lambda=3.2)$ and the combined turbines $(\lambda=2.9)$.

\section{Conclusions}

We studied the hydrodynamic characteristics of a Darrieus-Savonius combined turbine 
for tidal power generation to improve the starting performance of the solo Darrieus turbine. To accomplish this, the hydrodynamic characteristics of a semi-circular section used as the bucket of the Savonius rotor were first studied in the wind tunnel. Then, the torque of the Darrieus-Savonius combined turbines and solo Darrieus turbine were measured by a dynamometer in a circular water channel. The performance of the starting torque of the combined turbines was greatly improved. The attachment angle between the Darrieus wing and Savonius rotor was found to be important in the starting torque of the combined turbine. However, the power coefficient of the combined turbines was decreased to $70 \%$ of the solo Darrieus turbine near the rotational velocity ratio $\lambda=2.2$, where the turbine is expected to operate. To solve this problem, a ratchet mechanism attached to the Savonius rotor was tested but was found ineffective in improving the power coefficient. The reason for this may be the flow field change due to the Savonius rotor, which might reduce the torque generated by the Darrieus wings.

Lastly, power generation experiments using a 48 pole electric generator were conducted in the towing tank and the total performance of the power system was confirmed.

From these studies, we conclude that one of the recommended alignments of the Darrieus-Savonius turbine should not be coaxial but should be independent in the axial direction, so that the total performance of the combined turbine can be expected by the superposition of each turbine involved.

\section{Acknowledgements}

A part of this research was supported by a Grant-in-aid for Scientific Research, Basic Research (A), 17206087, 2005-2007, from the Japan Society for the Promotion of Science (JSPS). The author would like to thank Messrs. H. Akira and Y. Urakata for their contribution to carrying out the experiments in this study.

\section{References}

(1) Kiho, S. and Shiono, M.: Tidal power generation by a Darrieus water turbine in Kurushima channel, Trans IEE Japan, 1992; 112-D. (in Japanese)

(2) Kyozuka, Y. et al., Hydrodynamic Characteristics of a Darrieus Water Turbine for Tidal Power Generation, J. Japan Soc. Naval Arch. Ocean Eng., Vol.4, (Dec. 2006), pp.39-45.

(3) Shiono M. et al., Output Characteristics of Power Generation System from Tidal Current for a Navigation Buoy, Proc. $17^{\text {th }}$ Int. Offshore and Polar Eng. Conf., CD-ROM, (July 2007), pp.288-292.

(4) Torii, T. et al., A Study on Effectiveness of Straight-wing Vertical Hydro Turbine Generation System in the Tidal Current, Proc. $17^{\text {th }}$ Int. Offshore and Polar Eng. Conf., CD-ROM, (July 2007), pp.297-301.

(5) Sheldahl, R.E. et al., Wind Tunnel Performance Data for Two- and Three-Bucket Savonius Rotors, J.ENERGY, Vol.2, No.3, (May-June 1978), pp.160-164.

(6) Seki, K. and Otani, I.: Performance of Straight Blade, Non-Articulated Vertical Axis Wind Turbine, Journal of JSES, Vol.16, No.3, 1990. (in Japanese) 